\title{
Evaluating Therapy Treatments in Patients with Mental Disorders in Relation to Oral Health
}

\author{
Mimoza Canga ${ }^{1}$, Irene Malagnino ${ }^{2}$, Giulia Malagnino ${ }^{3}$, Vito Malagnino ${ }^{4}$
}

\begin{abstract}
Aim: The purpose of this study was to find the correlation between dental caries and teeth loss in relation to gender, age, treatments with different therapies, time period being hospitalized, sugar consumption, smoking, and oral hygiene in mental disordered patients.

Objective: Evaluating therapeutic treatments in patients with mental illnesses, focusing on the effects on oral health.

Materials and methods: This is a longitudinal cohort study conducted on patients who have been hospitalized from 5 years to 30 years. Patients were observed for 7 months (January 2019-July 2019) in the psychiatric hospital "Ali Mihali", in Vlora, Albania. In our study, 200 patients participated, of which 103 were females (51.5\%) and 97 were males (48.5\%).

Results: In the present study, we analyzed the oral health of patients within the age class of 30-70 years. We divided them into four age groups: $30-40,41-50,51-60$, and $61-70$ years. According to the ANOVA test, a strongest influence on caries manifestation and missing teeth was noticed during the time the patient was being hospitalized, with $p$ values $=0.000$ in both cases. The treatments done with different therapies also had a strong influence on the teeth loss with a $p$ value $=0.001$, while in carious teeth the $p$ value was 0.004 . This study showed that there is a strong statistically significant correlation between sugar consumption and smoking, in relation to caries manifestation and teeth loss, with $p$ values $=0.000$, respectively.

Conclusion: These patients are a vulnerable group, if we consider their oral health. The present study proved that the most important reasons for their poor dental health are: bad oral hygiene, smoking, sugar consumption, adverse effects of medications, and the time period that these patients have been hospitalized.

Clinical significance: By knowing the factors that have worsened the oral health of mental disordered patients, we can try to raise the awareness about caries reduction and to avoid teeth loss.
\end{abstract}

Keywords: Dental caries, Longitudinal study, Mental health, Teeth extraction, Treatment duration.

The Journal of Contemporary Dental Practice (2019): 10.5005/jp-journals-10024-2678

\section{INTRODUCTION}

Oral health has significant consequences in the life quality of mental disordered patients. These patients have poor oral hygiene, have problems with both speaking and eating, and may manifest other complications. ${ }^{1,2}$

Dental caries is one of the most prevalent chronic diseases of people in different parts of the world. Dental caries is an infectious disease that causes teeth loss. Sugar consumption, smoking, poor oral hygiene, and insufficient fluoride exposure are some of the reasons why mental disordered patients have dental caries. ${ }^{3}$

A strong relation exists between oral health and mental health. ${ }^{4}$

People with severe mental illnesses such as dementia and schizophrenia are at a greater risk of oral health problems because of a heavy consumption of sugary food and carbonated drinks. The use of different medicaments, such as haloperidol, risperdal, olanzapine, diazepam, lithium carbonate, have their own secondary effects because they are strong psychotropic medications, such as antipsychotics, antidepressants, and mood stabilizers. ${ }^{5-8}$

Mental ill patients are more at risk of oral and dental diseases, compared to the general population. This is due to the lack of selfcare and because they have limited access to health services. ${ }^{6}$ The goal of this study was to provide enough data about dental caries and teeth loss, in relation to sugar consumption, smoking, teeth brushing, treatments with different medicaments, and the period of time that these patients have been hospitalized. We analyzed oral and dental problems in patients with depression, anxiety, schizophrenia, and bipolar dementia.
${ }^{1}$ Faculty of Public Health, University “Ismail Qemali” Vlora, Albania

${ }^{2,3}$ Private Medical Services, Rome, Italy

"University "Gabriele D’Annunzio" Chiety, Italy

Corresponding Author: Mimoza Canga, Faculty of Public Health, University "Ismail Qemali" Vlora, Albania, Phone: +355 676502493, e-mail: mimoza-canga@hotmail.com

How to cite this article: Canga M, Malagnino I, Malagnino G, et al. Evaluating Therapy Treatments in Patients with Mental Disorders in Relation to Oral Health. J Contemp Dent Pract 2019;20(10):1179-1183.

Source of support: Nil

Conflict of interest: None

Xerostomia, or otherwise referred as the dryness of the mouth, may be a side effect of commonly used psychotropic medications. That's why it is considered as a major risk factor of oral health problems in mental disordered patients. ${ }^{9-11}$

Oral health issues should be taken more into consideration among people with severe mental illnesses, in order to minimize dental caries and teeth loss.

The aim of this study was to find out the correlation between dental caries and teeth loss, in relation to gender, age, treatments with different therapies, time period being hospitalized, sugar consumption, smoking, and oral hygiene, in mental disordered patients. The objective of this study was to evaluate oral health in patients with mental illnesses.

(c) The Author(s). 2019 Open Access This article is distributed under the terms of the Creative Commons Attribution 4.0 International License (https://creativecommons. org/licenses/by-nc/4.0/), which permits unrestricted use, distribution, and non-commercial reproduction in any medium, provided you give appropriate credit to the original author(s) and the source, provide a link to the Creative Commons license, and indicate if changes were made. The Creative Commons Public Domain Dedication waiver (http://creativecommons.org/publicdomain/zero/1.0/) applies to the data made available in this article, unless otherwise stated. 


\section{Materials and Methods}

This is a longitudinal cohort study. The time that our patients have been hospitalized starts from 5 years to 30 years. Patients were observed for a period of 7 months (January 2019-July 2019) in the psychiatric hospital "Ali Mihali", in Vlora, Albania. In our study 200 patients participated, of which 103 were females (51.5\%) and 97 were males (48.5\%). All the sample included in this study suffered from severe mental illnesses. During this study, we observed the effects of several medicaments such as haloperidol, parkopan, chlorpromazine, risperidal, lithium carbonate, and olanzapine in the oral cavity.

The inclusion criterion was that patients had to be hospitalized from 5 years to 30 years. Their age range was $30-70$ years. While the exclusion criterion was that patients who have stayed less than 5 years and more than 30 years in this hospital were not taken in consideration in this study. The study had no dropouts.

During the study we elicited information about: how frequent the patients have been to the dentist, their treatments with different medicaments, period of time being hospitalized, smoking, teeth brushing, and sugar consumption.

Our study was conducted in accordance to Helsinki declaration. ${ }^{12}$ On the basis of the Helsinki declaration issued by the World Medical Association, our research, which was on human participants, was clearly formulated in experimental protocols. In our study we took the consent of the director of the psychiatric hospital. The permission was obtained in the written form, which allowed us to perform the observations. Also, the present study was approved by the institutional board of the University of Vlora, Albania.

\section{Statistical Analysis}

Statistical analysis was performed using IBM SPSS Statistics 23.0. Data were analyzed with the ANOVA-test (analysis of variance). The significance level $(a)$ was set at 0.05 .

\section{Results}

In the present study, we analyzed the teeth of the patients within the age class of 30-70 years, who suffered from severe mental disorders. We divided them into four age groups: $30-40$ years, 41-50 years, $51-60$ years, and $61-70$ years. After the verifications were done with the patients of these group ages, we found out that the manifestation of dental caries and teeth loss was inevitable and also it differed at different ages. Data about caries development are presented in percentages.

The most affected age group by mental disorders was 51-60 years, with 69 patients or $34.5 \%$ (Table 1).

On the basis of our data there was a strong gender influence on teeth loss and dental caries manifestation, with a $p$ value 0.001 and 0.002 , respectively (Table 2 ).

The results of our study showed that the influence of the age variable was stronger in the missing teeth, having a $p$ value $=0.000$, in comparison to the manifestation of dental caries, which had a $p$ value of 0.007 (Table 2 ).

According to our statistical analysis, the treatments done with different therapies had a strong influence over teeth loss, with a $p$ value of 0.001 , while in carious teeth the $p$ value was 0.004 . These data proved a statistical significance (Table 2).

According to the ANOVA test, the period of time being hospitalized had the strongest influence on caries manifestation and teeth loss, with $p$ values $=0.000$, respectively.
This study also showed that there is a strong statistically significant correlation between sugar consumption and smoking, in relation to dental caries manifestation and teeth loss, with $p$ values of 0.000 in both cases (Table 2 ).

On the other hand, teeth brushing had a statistically significant correlation with teeth loss ( $p$ value $=0.01$ ), while in relation to dental caries the $p$ value was 0.04 (Table 2 ).

The analysis of this study proved that there is no statistically significant correlation between the treatments with different therapies in relation to gender and age, with a $p$ value of 0.908 and 0.152 , respectively (Table 3 ).

The results of our study showed that haloperidol, parkopan, and chlorpromazine were administered from $78 \%$ of the patients, whereas the remained $22 \%$ were treated with risperdal, lithium carbonate, and olanzapine (Fig. 1).

Table 1: Characteristics of the sample subjects who participated in this study

\begin{tabular}{ll}
\hline Subjects & $n(\%)$ \\
\hline Gender & \\
Female & $103(51.5 \%)$ \\
Male & $97(48.5 \%)$ \\
Age (years) & \\
$30-40$ & $36(18 \%)$ \\
$41-50$ & $56(28 \%)$ \\
$51-60$ & $69(34.5 \%)$ \\
$61-70$ & $39(19.5 \%)$ \\
Period of time staying hospitalized (in years) & \\
5 & $22(11 \%)$ \\
$6-10$ & $10(5 \%)$ \\
$11-15$ & $32(16 \%)$ \\
$16-20$ & $44(22 \%)$ \\
$21-25$ & $42(21 \%)$ \\
$26-30$ & $50(25 \%)$ \\
\hline
\end{tabular}

Table 2: Correlation of the factors that cause dental caries and teeth loss

\begin{tabular}{lll}
\hline & Dental caries & Teeth loss \\
\cline { 2 - 3 } & pvalue & $p$ value \\
\hline Gender & 0.002 & 0.001 \\
Age & 0.007 & 0.000 \\
Treatment with therapy & 0.004 & 0.001 \\
Period of time staying & 0.000 & 0.000 \\
hospitalized (in years) & & \\
Sugar & 0.000 & 0.000 \\
Smokers & 0.000 & 0.000 \\
Teeth brushing & 0.04 & 0.01 \\
\hline
\end{tabular}

Table 3: Relation between treatments with different therapies, gender and age

\begin{tabular}{ll}
\hline \multirow{3}{*}{ Subjects } & $\begin{array}{l}\text { Treatments with different } \\
\text { therapies }\end{array}$ \\
\cline { 2 - 2 } & $p$ value \\
\hline Gender & 0.908 \\
Age & 0.152 \\
\hline
\end{tabular}




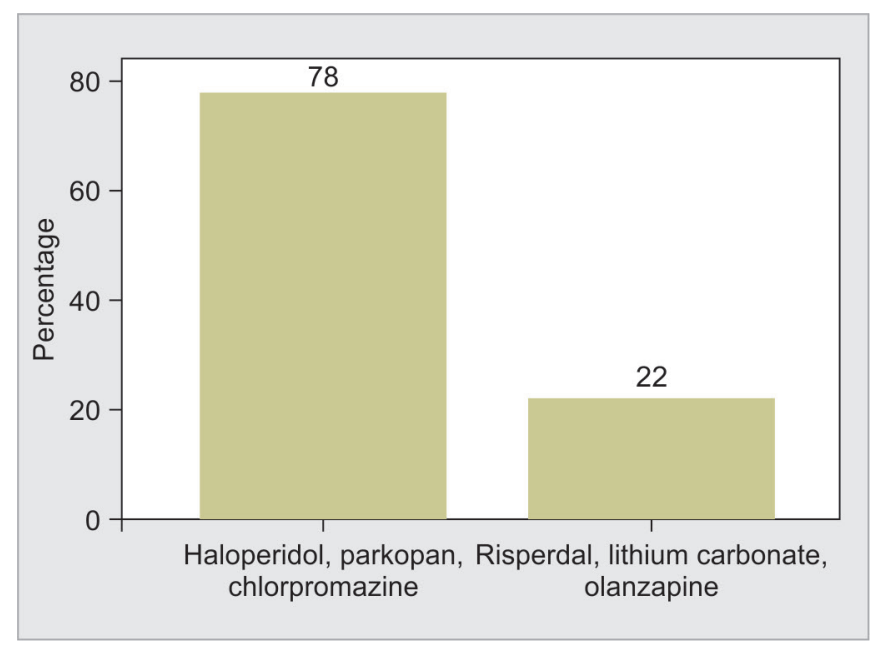

Fig. 1: Shows in percentage the treatments used in mental disordered patients

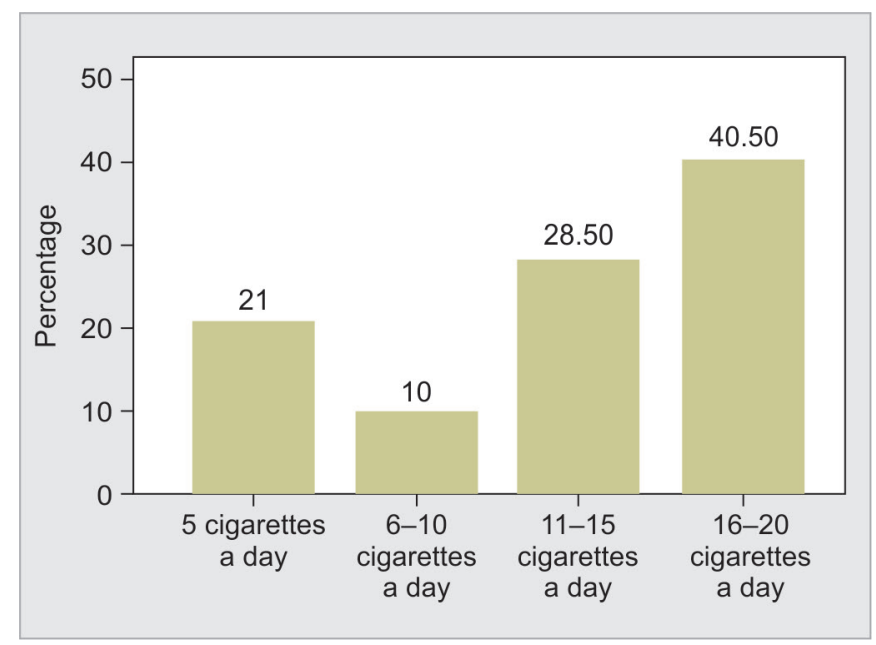

Fig. 3: Shows in percentage the number of cigarettes smoked during a day

The present study proved that $41.50 \%$ of the patients consumed food and drinks that are high in sugar daily (Fig. 2).

Our data also claimed that $40.50 \%$ of the patients with mental illnesses smoked 16-20 cigarettes per day (Fig. 3).

On the basis of the examinations of the present study, $68 \%$ of the patients had a poor oral hygiene. They brushed their teeth only once a day (Fig. 4).

Our investigation also showed that $47.5 \%$ of the patients had 6-10 missing teeth (Fig. 5).

\section{Discussion}

According to the data found on the official website of the Public Health Institute in Albania, only during the 2018, thousands of people across the country went to mental health centers.

The record is held by Tirana, where, according to the data of the Public Health Institute, there was a prevalence of over 3,700 mental ill patients in 100,000 people. Again, on the basis of those data, we can claim that $58 \%$ of these patients were women and $42 \%$ of them were men.

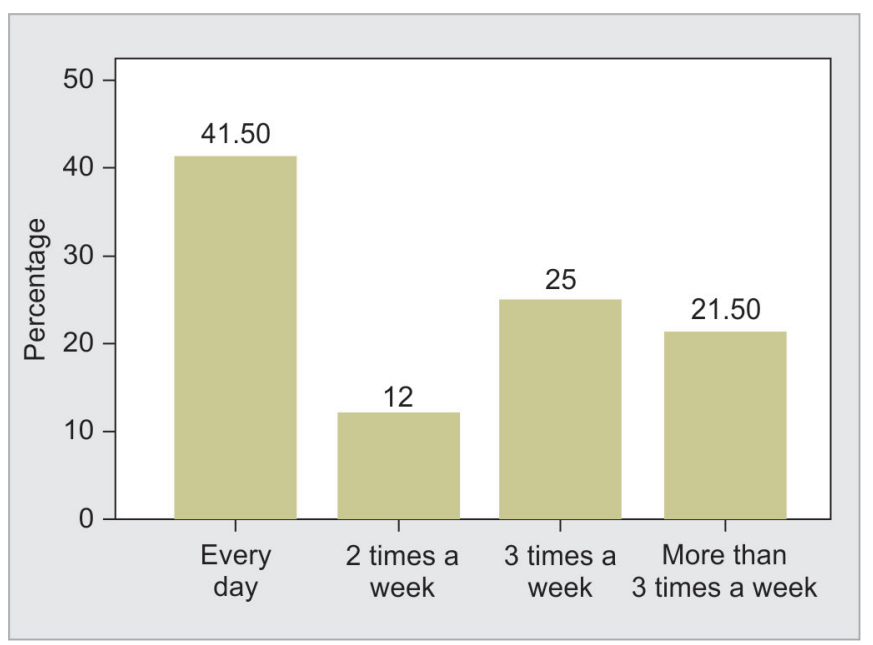

Fig. 2: Describes in percentage the distribution of sugar consumption

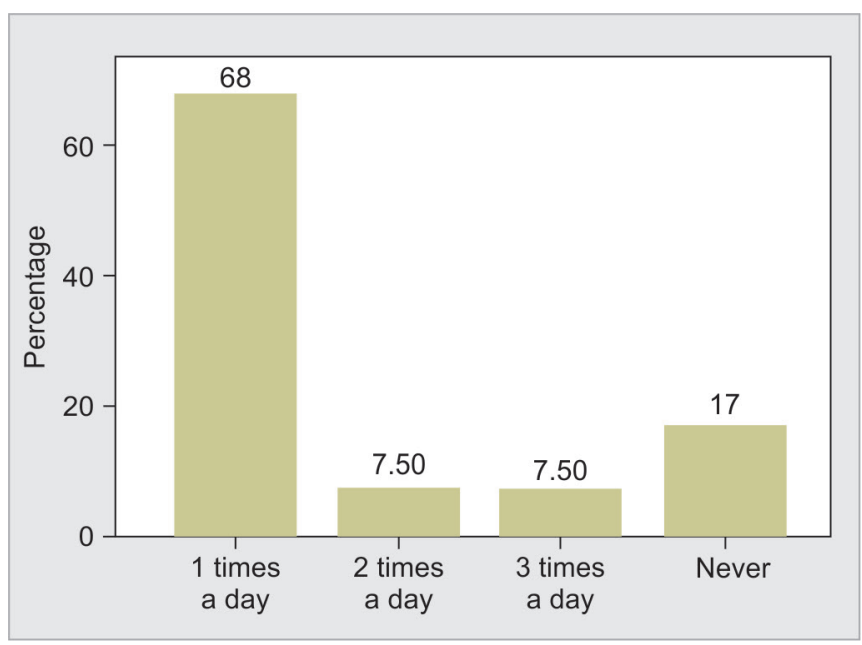

Fig. 4: Shows in percentage the frequency of teeth brushing

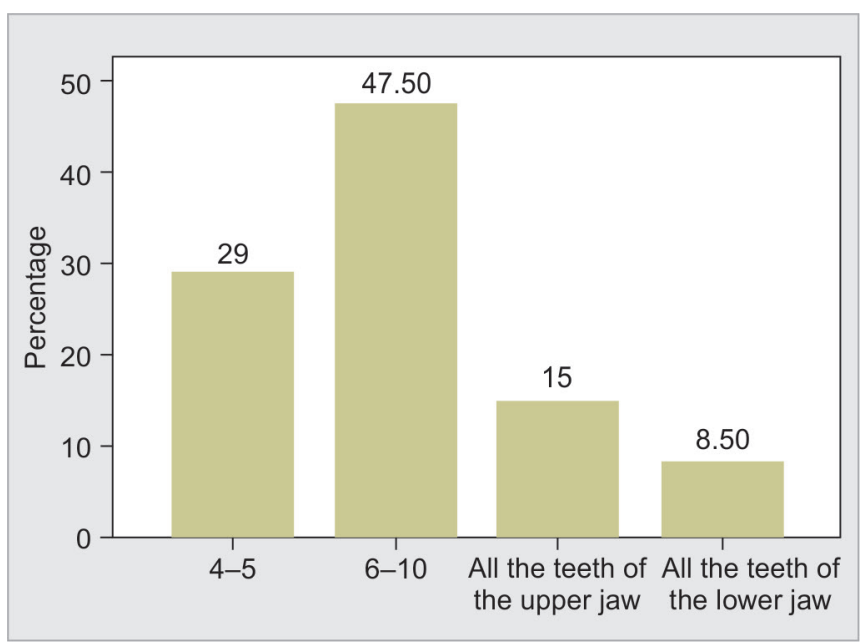

Fig. 5: Shows in percentage the number of the missing teeth in the oral cavity 
In 2016, the national program of free basic health control was implemented in Albania and the service was extended on the age range of 35-70 years. Over a thousand of citizens per day get benefit from this service and it provides opportunities for free base control for all the population.

Although all the efforts done by the Ministry of Health, the Albanian people do not consider oral health as something important, as they go to the dentist only when they feel pain. The oral health of Albanians is underestimated, despite dentists' advice to have consultations twice a year or to brush the teeth regularly 2-3 times per day. People still continue to neglect oral health.

The situation is worse, if we talk about people with mental disorders. This study found out that these patients had poor oral hygiene, a high degree of sugar intake, they were regular smokers, and they suffered from medicament side effects. Similar data were found by Swager et al. and Garima et al. ${ }^{13,14}$

According to Kisely et al., ${ }^{15}$ mental ill patients have three times more risk of having their teeth removed.

The present study showed that $47.5 \%$ of mental disordered patients had 6-10 missing teeth, other $15 \%$ of these patients had lost all the teeth of the upper jaw, whereas $8.5 \%$ of them had lost all the teeth of the lower jaw.

Kelly et al., ${ }^{16}$ claimed that $90 \%$ of the patients with mental disorders smoked. Similar data were found in the present study, only with differences in the number of cigarettes our patients smoked during a day. On the basis of our data, $40.5 \%$ of the patients smoked 16-20 cigarettes per day.

Different studies came at the conclusion that mental illnesses are very prevalent in the population of Australia (17.6\%) and according to them, these type of pathologies will be the second cause of morbidity in $2020 .^{17,18}$

Furthermore, several studies conducted in Singapore and Finland stated that one in four people will suffer an episode of mental disorder during their lifetime. They also claimed that undiagnosed people or people who don't undergo any treatment have a worsening of their disease. ${ }^{19,20}$

Many of the patients taken under observation, in the present study, suffered from schizophrenia, which is a chronic and severe disease. A study conducted by Barnes et al. ${ }^{21}$ on patients with schizophrenia showed that $61 \%$ of these patients had poor oral hygiene. These data are similar to our findings, which showed that $68 \%$ of the patients taken under observation had the same problem. According to Barnes et al., ${ }^{21}$ there is enough evidence showing that mental ill people present worse dental health in comparison to the general population. As proved by Kiwoong et al., ${ }^{22}$ and José et al., ${ }^{23}$ poor oral hygiene can lead to teeth loss.

Grinshpoon et al. ${ }^{24}$ found an association between the type of antipsychotic medications administered and oral hygiene. Their study stated that antipsychotics are more likely to cause extrapiramidal symptoms, which affect the process of teeth brushing. However, these symptoms were not taken into consideration in the present study.

Mental health clinicians consider that oral health should be part of a comprehensive assessment of people with severe mental disorders. ${ }^{25}$

This study proved that the medicaments administered by mental ill patients caused xerostomia, and their side effects lead to the manifestation of dental caries, teeth loss, and oral infections. ${ }^{26-28}$ Patients stated that their saliva was decreased and they had troubles while swallowing, speaking, or eating dry foods. That's why the use of psychotropic medications should be monitored.
There are data concerning the poor oral health of people with mental illnesses, but yet, it still remains a largely forgotten problem, especially in Albania. Even in many developed countries of the world, universal health care does not cover dental treatment.

In our study, we used the ANOVA-test analysis to prove that sugar consumption was significantly correlated with dental caries and teeth loss $(p=0.000)$. Our data are similar to the results achieved by Henderson et al. ${ }^{29}$

Findings of the current study proved that $33 \%$ of the patients with mental disorders go to the dentist only when they feel pain. That's why there is a high number of carious and missing teeth among these patients. In their study, Grant et al. ${ }^{30}$ had the same conclusions, as we had.

The oral health situation of mentally ill patients should raise the awareness that this group of people is at a high risk of dental problems. The present study recommends that these patients should be considered as particularly vulnerable and dentists should go and check their patients regularly.

But, we cannot neglect the fact that the number of psychiatrists in Albania is very low; there are only 3 psychiatrists per 100,000 inhabitants. Our recommendation is to increase the number of psychiatrists to better monitor these patients.

Considering that oral health is a very important part of the wellbeing of patients with mental disorders, we should focus on providing these patients a multidisciplinary attention, which includes, dentists, psychologists, nutrition professionals, and psychiatrists. Also, it is advisable that the dentists should contact the treating psychiatrists before initiating any medications.

This study is limited only on patients that are treated with these types of medicaments, such as haloperidol, parkopan, chlorpromazine, risperdal, lithium carbonate, and olanzapine. Another limitation of this study was that patients who had been there less than 5 years and more than 30 years were not taken into consideration. Also, the age range can be seen as a limitation because patients younger than 30 years and older than 70 years were excluded from the study.

\section{Conclusion}

We can state that these patients are a vulnerable group, if we consider their oral health. The present study proved that the most important reasons for their poor dental health are bad oral hygiene, smoking, sugar consumption, adverse effects of medications, and the time period that these patients have been hospitalized.

\section{Clinical Significance}

We can try to raise the awareness about caries reduction and avoiding teeth loss by knowing the factors that have worsened the oral health of mental disordered patients.

\section{Acknowledgments}

I want to thank my colleagues, and especially, professor Vito Malagnino for his support of and contribution to this study.

\section{References}

1. Mirza RD, Phelan M, Wulff-Cochrane V. Oral health of psychiatric in-patients. Psychiatr Bull 2001;25:143-145. DOI: 10.1192/pb.25.4.143.

2. Selwitz RH, Ismail Al, Pitts NB. Dental caries. Lancet 2007 Jan 6;369(9555):51-59. DOI: 10.1016/S0140-6736(07)60031-2. 
3. Scannapieco FA. Systemic effects of periodontal diseases. Dent Clin North Am 2005;49(3):533-550. DOI: 10.1016/j.cden.2005.03.002.

4. Coculescu E, Radu A, Coculescu B. Burning mouth syndrome: a review on diagnosis and treatment. Med Life J 2014;7(4):512-515.

5. Bardow A, Nyvad B, Nauntofte B. Relationships between medication intake, complaints of dry mouth, salivary flow rate and composition, and the rate of tooth demineralization in situ. Arch Oral Biol J 2001;46(5):413-423. DOI: 10.1016/S0003-9969(01)00003-6.

6. Lewis $S$, Jagger RG, Treasure $E$. The oral health of psychiatric in-patients in South Wales. Spec Care Dentist J 2001;21(5):182-186. DOI: 10.1111/j.1754-4505.2001.tb00252.x.

7. Ramon T, Grinshpoon A, Zusman SP, et al. Oral health and treatment needs of institutionalized chronic psychiatric patients in Israel. Eur Psychiatry J 2003;18(3):101-105. DOI: 10.1016/S0924-9338(03)00023-3.

8. Lalloo R, Kisely $\mathrm{S}$, Amarasinghe $\mathrm{H}$, et al. Oral health of patients on psychotropic medications: a study of outpatients in Queensland. Australas Psychiatry 2013;21(4):338-342. DOI: 10.1177/1039856213486308.

9. Boyle C, Koburunga S. Dental care for adults with mental health problems. Dental Nursing J 2012;8(8):482-486. DOI: 10.12968/ denn.2012.8.8.482.

10. Milosevic A. Eating disorders and the dentist. Br Dent J 1999;186(3): 109-113. DOI: 10.1038/sj.bdj.4800036.

11. Bretz W. Oral profiles of bulimic women: diagnosis and management: What is the evidence? J Evid Based Dent Pract 2002;2(4):267-272. DOI: 10.1016/S1532-3382(02)70078-X.

12. John RW. The Declaration of Helsinki and public health. Bull World Health Organ 2008 Aug;86(8):650-652. DOI: 10.2471/BLT.08. 050955.

13. Swager LW, Morgan SK. Psychotropic-induced dry mouth: don't overlook this potentially serious side effect. Curr Psychiatry J 2011;10(12):54.

14. Garima A, Mackay DF, Conway DI, et al. Ethnic differences in oral health and use of dental services: cross-sectional study using the 2009 Adult Dental Health Survey. BMC Oral Health J 2017;17:1. DOI: 10.1186/s12903-016-0228-6.

15. Kisely S, Quek LH, Pais J, et al. Advanced dental disease in people with severe mental illness: systematic review and meta-analysis. Br J Psychiatry 2011;199(3):187-193. DOI: 10.1192/bjp.bp.110. 081695.

16. Kelly C, McCreadie RG. Smoking habits, current symptoms, and premorbid characteristics of schizophrenic patients in Nithsdale, Scotland. Am J Psychiatry 1999 Nov;156(11):1751-1757. DOI: 10.1176/ ajp.156.11.1751.
17. Page $M$, Somerville-Brown L. Psychotropic drugs and dentistry. Aust Prescr 2007;30(4):98. DOI: 10.18773/austprescr.2007.059.

18. Steel Z, Marnane C, Iranpour C, et al. The global prevalence of common mental disorders: a systematic review and meta-analysis 1980-2013. Int J Epidemiol 2014 Apr;43(2):476-493. DOI: 10.1093/ije/ dyu038.

19. Kauppi $\mathrm{K}$, Hätönen $\mathrm{H}$, Adams $\mathrm{CE}$, et al. Perceptions of treatment adherence among people with mental health problems and health care professionals. J Adv Nurs 2015 Apr;71(4):777-788. DOI: 10.1111/ jan.12567.

20. Arulkumaran S. Health and Human Rights. Singapore Med J 2017 Jan;58(1):4-13. DOI: 10.11622/smedj.2017003.

21. Barnes GP, Allen EH, Parker WA, et al. Dental treatment needs among hospitalized adult mental patients. Spec Care Dentist J 1988;8(4): 173-177. DOI: 10.1111/j.1754-4505.1988.tb00726.x.

22. Kiwoong P, Tse-Chuan Y. The Long-term Effects of Self-Esteem on Depression: The Roles of Alcohol and Substance Uses during Young Adulthood. Sociol Q 2017;58(3):429-446. DOI: 10.1080/00380253.2017.1331718.

23. José AGM, Ana LF, Rocío B, et al. Oral health in the elderly patient and its impact on general well-being: a non-systematic review. Clin Interv Aging 2015;10:461-467. DOI: 10.2147/CIA.S54630.

24. Grinshpoon A, Zusman SP, Weizman A, et al. Dental Health and the Type of Antipsychotic Treatment in Inpatients with Schizophrenia. Isr J Psychiatry Relat Sci 2015;52(2):114-118.

25. Chalmers JM, King PL, Spencer AJ, et al. The Oral Health Assessment Tool—validity and reliability. Aust Dent J 2005;50(3):191-199. DOI: 10.1111/j.1834-7819.2005.tb00360.x.

26. Solanki J, Khetan J, Gupta S, et al. Oral Rehabilitation and Management of Mentally Retarded. J Clin Diagn Res 2015 Jan;9(1):ZE01-ZE06.

27. Julio T, Iván B, Israel G. Oral and dental health issues in people with mental disorders. Medwave J 2017 Sep;17(8):7045. DOI: 10.5867/ medwave.2017.08.7045.

28. Alessandro V, Christopher LC, Silvio A. Diagnosis and management of xerostomia and hyposalivation. Ther Clin Risk Manag 2015;11:45-51. DOI: $10.2147 / T C R M . S 76282$.

29. Henderson DC, Sharma B, Fan X, et al. Dietary saturated fat intake and glucose metabolism impairments in nondiabetic, nonobese patients with schizophrenia on clozapine or risperidone. Ann Clin Psychiatry 2010 Feb;22(1):33-42.

30. Grant E, Carlson G, Cullen-Erickson M. Oral health for people with intellectual disability and high support needs: positive outcomes. Spec Care Dentist 2004 Mar-Apr;24(2):70-79. DOI: 10.1111/j.17544505.2004.tb01682.x. 